\title{
A videoanálise como mediadora da modelagem científica no Ensino de Mecânica
}

Nestor Cortez Saavedra Filho nestorsf@utfpr.edu.br 0000-0003-4139-8986 Universidade Tecnológica Federal do Paraná, Departamento Acadêmico de Física- Brasil

Jorge Alberto Lenz lenz@utfpr.edu.br 0000-0002-9557-9267 Universidade Tecnológica Federal do Paraná, Departamento Acadêmico de Física- Brasil

Arandi Ginane Bezerra Jr arandi@utfpr.edu.br 0000-0002-5145-5131

Universidade Tecnológica

Federal do Paraná,

Departamento Acadêmico de Física- Brasil

Marcos Antonio Florczak

florczak@utfpr.edu.br

0000-0002-3874-1926

Universidade Tecnológica

Federal do Paraná,

Departamento Acadêmico de

Física-Brasil

Vinicius Geovane Garcia vinicius geovane@hotmail.com 0000-0001-6746-1782

Universidade Tecnológica

Federal do Paraná-Campus

Curitiba-Brasil

\section{RESUMO}

Metodologias de ensino e aprendizagem mediadas por tecnologias de informação e comunicação (TIC) ocupam lugar de destaque nas discussões sobre a escola neste século. O Laboratório Didático, por sua vez, é um local onde são desenvolvidas metodologias articuladas com as TIC. No ensino de Mecânica a modelagem científica surge como alternativa ao estudo de situações apenas "ideais", nem sempre próximas da realidade prática. Neste trabalho discutimos estratégias baseadas no uso da videoanálise para o desenvolvimento de atividades experimentais com vista a incorporar a modelagem científica nas aulas de Mecânica. Demonstramos que o uso do software livre Tracker, enquanto TIC mediadora de atividades experimentais permite a inclusão de elementos que instigam a uma modelagem mais elaborada, favorecendo situações de aprendizagem que remetem a um conhecimento menos fragmentado, mais contextualizado e a uma visão mais ampla e referenciada da ciência.

PALAVRAS-CHAVE: Atividades Experimentais no Ensino de Mecânica, Tecnologias de Informação e Comunicação, Objetos de Aprendizagem, Videoanálise, Modelagem Científica, Tracker. 


\title{
INTRODUÇÃO
}

A modelagem científica consiste em um processo que está na base de produção do conhecimento das ciências naturais e das engenharias, estando assim sobreposta com os conteúdos disciplinares a serem aprendidos (BRANDÃO et al, 2011). Neste sentido, a modelagem científica poderia ser uma estratégia didática norteadora do planejamento de atividades experimentais no ensino de ciências e engenharias, para o desenvolvimento de atividades experimentais que favoreçam a aquisição de concepções e competências em Física. Este desenvolvimento constitui um desafio interessante para os pesquisadores desta área de ensino. Segundo Brandão e colaboradores (2011):

\begin{abstract}
No "ensino tradicional" costuma-se alertar o estudante de que a realidade é demasiada complexa. Em seguida, justifica-se, por meio de argumentos didático-pedagógicos, que o conteúdo será introduzido através de situações altamente idealizadas com o intuito de que, em um futuro próximo, muitas vezes jamais alcançado, o estudante será capaz de compreender as situações mais realísticas (p.532).
\end{abstract}

Este discurso encontra ressonância em outras abordagens inovadoras, como a proposta por Cunha (2011), que aborda aspectos de complexidade e também do processo de ensino e aprendizagem na própria sala de aula. De fato, situações que fogem ao tradicional e causam eventuais conflitos podem ser mediadas pela modelagem científica, pois o ato de observar e tentar descrever um fenômeno da natureza incorre em sua modelagem e consequentes comprovações experimentais. Na formação do engenheiro-tratando-se aqui de uma abordagem fundamental, pois problemas complexos de engenharia não encontram "respostas prontas" -, devido às suas particularidades e complexidades intrínsecas, o pensar, descrever, modelar e experimentar são partes indeléveis entre as habilidades e competências a serem desenvolvidas (LAUDARES, PAIXÃO e VIGGIANO, 2008; SOUZA et al, 2015).

Um dos efeitos da não abordagem, em sala de aula, do processo de modelagem científica seria a dificuldade apresentada pelos estudantes com relação à aplicação do conhecimento físico para a descrição, leitura e interpretação do real. É neste contexto que entendemos que o uso do computador como instrumento mediador para aquisição de dados nos laboratórios didáticos de disciplinas de Física básica para Engenharias, bem como outras mais avançadas da matriz curricular destes cursos, possa ser inserido, permitindo e inspirando que sejam criadas situações de aprendizagem associadas a um conhecimento menos fragmentado e mais contextualizado. Desta forma, defendemos, neste trabalho, uma metodologia de aplicação da Modelagem Científica no Ensino de Física, que articule Objetos de Aprendizagem com o laboratório didático, mediado pela videoanálise, cujos conceitos passaremos a expor.

Tal metodologia constitui um caminho para uma descrição da realidade complexa com o que o futuro engenheiro ou professor de Física irá se deparar em sua vida profissional.

Os Objetos de Aprendizagem (OA), parte das Tecnologias de Informação e Comunicação (TIC), despontam como elementos inspiradores e norteadores de pesquisas no campo do Ensino de Ciências (WILEY, 2009; SENA DOS ANJOS, 2008; ARANTES et al. 2010). São várias as tentativas de abordar estas tecnologias 
enquanto portadoras de potencial para o ensino. Neste sentido, os mais diversos OA e TIC têm sido desenvolvidos para diversas atividades de modelagem e simulação, conforme disposto por Araújo, Veit e Moreira:

No contexto do ensino-aprendizado de Física, distinguimos as atividades computacionais de simulação e modelagem pelo acesso que os alunos têm aos primitivos que compõem o modelo computacional. Essas atividades podem ser desdobradas em quatro categorias:

a) Atividade exploratória de simulação - caracterizada pela observação, análise e interação do sujeito com modelos já construídos, que permitem que sejam alterados valores iniciais e parâmetros (e.g. Physlets).

b) Atividade exploratória de modelagem - definida pela análise da estrutura básica de um modelo computacional já construído. $\mathrm{O}$ aluno tem acesso aos primitivos do modelo e precisa descrevê-lo, corrigi-lo e/ou complementá-lo (e.g. um modelo no software Modellus).

c) Atividade expressiva de simulação - identificada pela elaboração de modelos computacionais a partir da configuração e ajuste de propriedades de macroelementos presentes em um repertório pré-definido (e.g. Phun, Interactive Physics).

d) Atividade expressiva de modelagem - caracterizada pelo processo de construção do modelo computacional desde sua estrutura lógica (regras lógicas), matemática (equações) ou icônica (metáforas). A construção de modelos computacionais com os aplicativos Worldmaker, LOGO (ou Modellus) e Stella, respectivamente, ilustra esse processo. (ARAÚJO, VEIT e MOREIRA, 2012, p. 346).

Desde que organizados em blocos, suas possibilidades de uso têm sido exploradas (HAAG, 2005; OPEN SOURCE PHYSICS, 2012). Além disso, também os efeitos da utilização das tecnologias têm sido investigados por meio de análises que visam a validar seu impacto e a apontar caminhos para o Ensino de Física (ROCHA et al, 2011), que, no contexto deste trabalho, pode ser visto no Ensino de Engenharia (OLIVEIRA e PASSOS, 2014), bem como a produção de OA para o Ensino de Engenharia propriamente dito (GAMA, SCHEER e SANTOS, 2008).

O laboratório didático de Física, por sua vez, representa outra questão central no ensino, porquanto diversas concepções foram e continuam sendo desenvolvidas, tendo em vista objetivos variados (PINHO ALVES, 2000), tanto fundamentados em visões tradicionais, bem como em outras abordagens, por exemplo, as baseadas em concepções construtivistas, nas quais as atividades experimentais teriam função mediadora no ensino dos conteúdos (PINHO ALVES, 2004).

\section{A Videoanálise e o software Tracker}

A análise de vídeo, ou videoanálise, é uma técnica que permite o registro de fenômenos que envolvam movimentos por meio de filmagens, as quais podem ser utilizadas em atividades experimentais para o ensino de Física (BARBETA e YAMAMOTO, 2002; BROWN e COX, 2009; BRYAN, 2010; CATELLI et al., 2010; CORVELONI et al., 2009), dado que, atualmente, é cada vez mais facilitado o acesso a câmeras digitais. 
Dentre as alternativas na utilização de videoanálise, o software livre Tracker (BROWN, 2012) tem sido apresentado com perspectivas e resultados promissores. O programa permite realizar análise de vídeos quadro a quadro, com o que é possível o estudo de diversos tipos de movimento a partir de filmes feitos com câmaras digitais ou webcams de computadores comuns e telefones celulares. É um software livre ligado ao projeto Open Source Physics (OSP, 2012), este relacionado ao desenvolvimento de programas com códigos abertos para o ensino de Física. O software fornece, automaticamente, os valores de distância a partir de um padrão (que pode ser uma escala graduada colocada no pano de fundo da filmagem) e também identifica automaticamente a quantidade de quadros por segundo empregadas pela câmera digital usada. Estes dados de posição e tempo são apresentados em uma tela que possibilita a análise e manipulação dos dados de forma simples e rápida. Por este motivo, a proposta do Tracker é adequada ao tempo e espaço de uma aula de laboratório de Física, ou mesmo como apoio a uma aula expositiva. Neste sentido, o uso do Tracker se mostra compatível com o desenvolvimento de atividades centradas no processo de modelagem científica. Aqui se destaca outra característica fundamental do Tracker: por ser um software livre, permite uma série de iniciativas relacionadas à sua apropriação pelos usuários como, por exemplo, a distribuição gratuita de cópias do programa, a tradução para idiomas de interesse e a elaboração de manuais de utilização, acarretando vantagens óbvias para seu uso e divulgação no ambiente escolar (OLIVEIRA et al., 2011). Adicionalmente, este tipo de interação, favorecida em uma comunidade de tecnologias livres, permite que o aprendizado ocorra de maneira mais diligente e crítica ao fazer com que os envolvidos no processo tornem-se sujeitos ativos na utilização destas tecnologias (MATSUNAGA, 2015; CELAYA e MARTíNEZ, 2007). Além disso, entende-se que o uso do Tracker esteja em sintonia com a modernização do saber escolar, num contexto em que as atividades experimentais teriam função mediadora no ensino dos conteúdos (PINHO ALVES, 2004).

Um procedimento comum nos laboratórios didáticos, alternativo à utilização da videoanálise, é a integração dos experimentos corriqueiros ao computador (DIONISIO e MAGNO, 2007). Contudo, tal abordagem frequentemente esbarra na falta de formação dos professores para sua utilização, pois envolve conceitos de eletrônica e programação de computadores nem sempre acessíveis aos docentes, além da ausência, em geral, de técnicos com tal formação específica nas escolas. Outra solução poderia ser a aquisição de pacotes fechados de experimentos didáticos a empresas do ramo, o que, além dos altos custos envolvidos, torna os usuários refém de pacotes tecnológicos fechados por uma série de protocolos e interfaces proprietárias que não permitem maiores alterações em seu uso nem inovações significativas nos experimentos propostos. Tais dificuldades podem ser superadas ao se fazer a opção por um software livre.

O Tracker pode ser instalado livremente e, além disso, é um software de fácil aprendizagem, o que torna relativamente simples seu uso na obtenção de informações relevantes em experimentos didáticos de Física Básica. Este OA cumpre várias funções no processo de ensino-aprendizagem: permite aos alunos acompanharem a evolução das grandezas físicas por meio de vídeos dos fenômenos reais, pondo fim à mera sequência de passos experimentais em roteiros de laboratórios estruturados ao extremo; permite a manipulação dos dados e construção dos gráficos a partir de tais observações, fundamental para a construção do conhecimento físico por meio de atividades experimentais e, 
finalmente, permite aos atores deste processo ser agentes ativos na construção, customização e adequação do programa às suas realidades, incluindo aí o seu uso tendo em vista a aquisição de concepções e competências associadas à modelagem científica.

Um procedimento típico mediado pelo uso do Tracker consiste na organização do experimento e na filmagem do movimento de interesse. Transfere-se, então, o arquivo de vídeo para o programa e faz-se a marcação dos pontos quadro a quadro. Os procedimentos necessários são explicados nos manuais presentes no programa (BROWN, 2012).

\section{O problema de estudo e a metodologia proposta para explorar a $2^{\mathrm{a}}$ lei de Newton}

Para desenvolver uma metodologia baseada em experimentos que contemplem a modelagem científica em aulas de Física, propomos, inicialmente, um trabalho de videoanálise relacionado à 2a Lei de Newton. Este é um tema fundamental da Física, abordado tanto nas disciplinas de Física Básica, no estudo da Mecânica, quanto naquelas de Mecânica Vetorial nos cursos de Engenharia. Por ser uma Lei notadamente empírica, a 2a Lei de Newton não dispõe de uma "dedução formal", de modo que a nossa proposta pretende fazer com o que os estudantes cheguem nesta Lei através de atividades que articulem o laboratório didático, as TIC e a modelagem científica.

A estratégia aqui proposta consiste em explorar uma situação recorrente nos livros de texto, e que se traduz num experimento simples: um carrinho (deslizando numa superfície horizontal) sendo tracionado por um cabo que, ao passar por uma polia, está preso a uma massa suspensa em sua outra extremidade. A Figura 1 ilustra a montagem experimental. A pertinência da utilização da videoanálise para este tipo de experimento vem de uma série de fatores. Um deles é, mesmo que a massa suspensa $M$ da Figura 1 seja pequena, comparada com a massa do carrinho, o movimento é suficientemente rápido para, sem a videoanálise, dificultar a percepção pelos estudantes da evolução temporal das grandezas físicas envolvidas neste tipo de movimento, mesmo porque, a aquisição de dados pelos estudantes é prejudicada por tal rapidez. Uma forma de contornar este obstáculo é a utilização de kits de materiais didáticos que fazem uso de sensores e um trilho com colchão de ar. Contudo, esta abordagem pode abstrair os estudantes da percepção da evolução temporal das grandezas físicas, causando um ruído epistemológico na aprendizagem dos conceitos relacionados ao experimento e movimento em questão, como, por exemplo, a influência do momento de inércia da polia. Outra dificuldade é o custo de tais kits de materiais didáticos, inacessíveis à maior parte das escolas básicas e mesmo muitas universidades brasileiras.

Quando a massa $M$ cai na direção vertical, o carrinho $(m)$ desloca-se na direção horizontal. O conjunto executa, então, um movimento acelerado que pode ser analisado com o auxílio do Tracker. Uma tela típica do software é apresentada na Figura 2. Os dados obtidos da distância percorrida em função do tempo podem ser analisados com os recursos do próprio Tracker ou com o auxílio 
aceleração do sistema em função de valores diferentes atribuídos à massa suspensa $(M)$. Este procedimento, por sua vez, tornará possível estabelecer, em sala, um diálogo com potencial unificador dos dados experimentais com a teoria Física representada pela segunda lei de Newton. Ao desprezar o atrito de rolamento e a massa da roldana, a análise do movimento, pelos procedimentos usuais de resoluções de problemas envolvendo as Leis de Newton, conduz à seguinte expressão para a aceleração do sistema, sendo g a aceleração da gravidade:

$$
a=\frac{M}{m+M} \mathrm{~g}
$$

Figura 1 - Experimento da Segunda lei de Newton. O sistema consiste por massa suspensa $(M)$ ligada por um fio ao carrinho $(m)$. Ao ser o carrinho liberado, o movimento é filmado e analisado com o Tracker

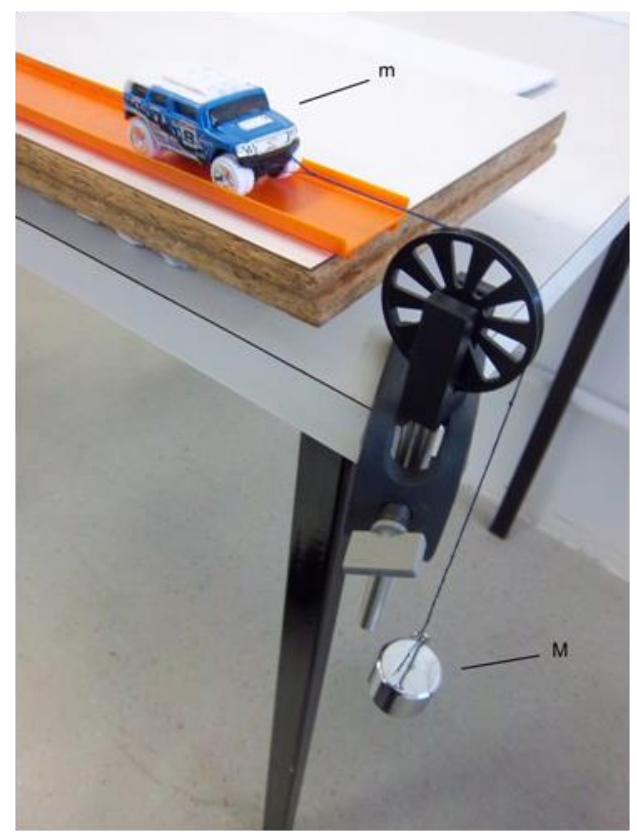

(Fonte: Autoria própria) 
Figura 2 - Tela do Tracker correspondente ao experimento proposto sobre a $2^{\text {a }}$ Lei de Newton. Os triângulos vermelhos são quadros sucessivos do movimento do carrinho. À direita, tem-se uma tabela com os dados de posição e tempo (abaixo) e o respectivo gráfico (acima)

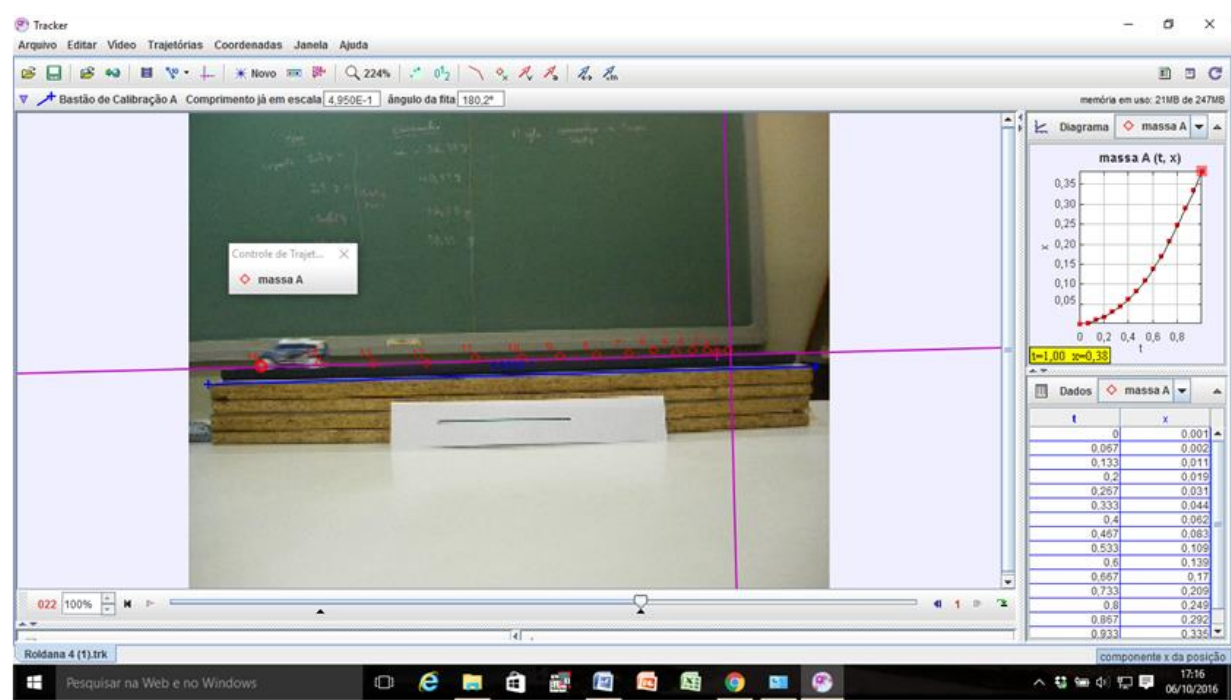

(Fonte: Autoria própria)

Note-se que, para cada valor da massa variável $M$, a análise dos dados da filmagem realizada pelo Tracker é utilizada para determinar a aceleração do sistema por meio de um gráfico de posição versus tempo. Com estes dados, é possível utilizar a equação (1) para realizar a regressão matemática dos valores experimentais, conforme mostrado na Figura 3.

Figura 3 - Dados experimentais obtidos com o Tracker para a aceleração do sistema em função das massas $M$ e $m$. Esta apresentação dos dados visa a dar evidência à equação

(1). Note o coeficiente linear negativo da reta

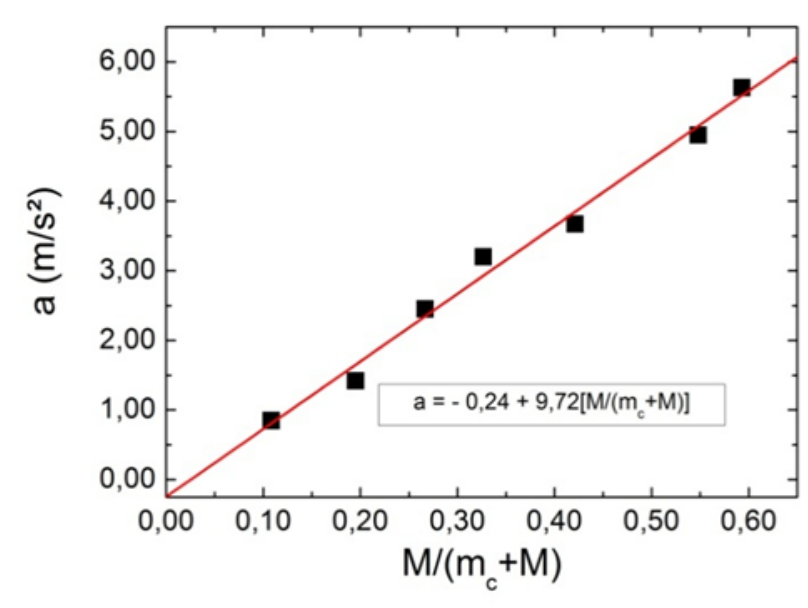

(Fonte: Autoria própria)

O gráfico ilustrado na Figura 3 permite o cálculo do valor da aceleração da gravidade no local do experimento, por meio do coeficiente angular da reta que corresponde à regressão matemática dos pontos. Tal procedimento forneceu o 
valor de $9,72 \mathrm{~m} / \mathrm{s}^{2}$, um bom parâmetro para validar o uso do Tracker na observação e descrição do movimento. Neste ponto, ao observar e realizar a regressão linear dos dados experimentais (reta em vermelho na Figura 3), utilizando a equação (1), surge um dado novo: a reta obtida apresenta coeficiente linear negativo. Este é um exemplo interessante em que a sensibilidade do professor e dos estudantes é chamada a dar significado físico à evidência experimental - o que exige habilidades e competências relacionadas à modelagem científica. Assim, cabe notar que os dados experimentais sempre incluem informações do "mundo real", porque, no sistema físico real (portanto, no experimento realizado) atuam as forças dissipativas (atrito, resistência do ar, etc.). Pois, ao (re)modelar o sistema, e ao incluir estas forças dissipativas na equação (1), a segunda lei de Newton, conduz a:

$$
a=\frac{M}{m+M} \mathrm{~g}-\frac{\mathrm{f}}{\mathrm{m}+\mathrm{M}^{\prime}}
$$

onde $f$ diz respeito às já mencionadas forças dissipativas, e o segundo termo à direita pode ser entendido como a contribuição associada a elas e chamado de $a_{d}$. Então, a equação (2) pode ser reescrita ainda como:

$$
a=\frac{M}{m+M} \mathrm{~g}-\mathrm{a}_{\mathrm{d}}
$$

Assim, nota-se facilmente que $a_{d}$ é o coeficiente linear da reta obtida a partir dos dados experimentais, ou seja, os efeitos do atrito estavam mesmo implicitamente incluídos nestes dados presentes "no mundo real", de modo que se faz necessário refinar o modelo matemático, associando ao coeficiente linear os efeitos dissipativos. Esta análise abre a possibilidade de uma discussão a respeito da força $f$ ser proporcional às massas $m$ e $M$.

Portanto, quando uma situação como esta aqui proposta é apresentada aos estudantes, surge a possibilidade de se abordar o processo de modelagem científica, ligando teoria e prática, relacionando modelo, representação e explicação.

Outra idealização frequentemente utilizada no ensino de Mecânica são as polias "ideais", para as quais são desprezados os atritos de rolamento e a massa, portanto, o momento de inércia ou inércia rotacional.

A equação (2) e, portanto, a equação (3) foi obtida aplicando-se a Segunda Lei de Newton relativa à translação para os corpos $M$ e $m$. Objetivando uma análise com um pouco mais de profundidade, pode-se levar em conta também a rotação da roldana. Desta maneira, aplicando-se também a segunda lei de Newton para a rotação da roldana de massa definida como $m_{R}$ e seu raio de $R$ (BEER, JOHNSTON, 1991), surge um novo termo adicionado ao denominador do coeficiente angular da equação (3), que passa a ser escrita como:

$$
a=\frac{M}{m+M+\alpha m_{R}} \mathrm{~g}-\mathrm{a}_{\mathrm{d}}
$$


Pode-se considerar que de um modo geral, as roldanas ou polias apresentam momento de inércia $(I)$ dado por:

$$
I=\alpha m_{R} R^{2}
$$

onde $\alpha$ é um coeficiente numérico compreendido entre zero e 1 e seu valor depende da geometria e distribuição de massa da roldana. Por exemplo, no caso de a roldana equivaler a um disco homogêneo, $\alpha=0,5$; e no caso da massa estar disposta nas bordas (como no caso de um anel), $\alpha=1$. A obtenção deste coeficiente de forma analítica requer a utilização de integrais de volume e uma disposição geométrica simétrica (BEER e JOHNSTON, 1991). Encontra-se aqui, portanto, um campo propício de aplicação da modelagem científica, de como obter a partir de um experimento o momento de inércia de uma peça que não tenha, necessariamente, um alto grau de simetria, uma situação com diversas aplicações em Engenharia.

Com o objetivo de estender esta abordagem e assim tentar modelar este aspecto, além da roldana com baixíssimo atrito de rolamento, denominada aqui de $\mathrm{R} 4$, foram realizadas atividades experimentais relativas à aplicação da segunda lei de Newton com outras três roldanas, com diferentes sistemas de rolamento, portanto, com diferentes níveis de atrito, denominadas de R1, R2 e R3. As imagens das mesmas estão ilustradas na Figura 4 e, na tabela 1, estão listadas as massas de cada uma delas.

Figura 4 - Visualização das roldanas utilizadas (a denominação atribuída a cada uma aparece acima de cada imagem)

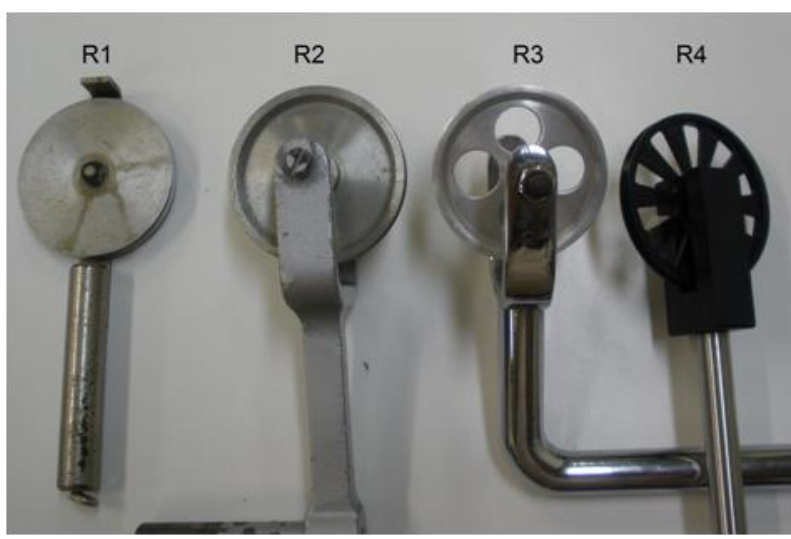

(Fonte: Autoria própria)

Tabela 1 - Valores das massas das roldanas utilizadas neste trabalho

\begin{tabular}{lcccc} 
Roldanas & R1 & R2 & R3 & R4 \\
\hline Massas (g) & 27,5 & 21,5 & 9,99 & 2,00
\end{tabular}


A Figura 5 apresenta gráficos com os dados experimentais obtidos com o Tracker para a aceleração do sistema em função das massas $M$ e $m$ para as três roldanas denominadas de R1, R2 e R3.Devido à presença de atrito na roldana R1, percebe-se claramente da dificuldade de ajuste dos dados na Figura 5(A). Com a roldana $\mathrm{R} 2$, os valores obtidos já se encontram dentro de uma faixa razoável de aceitação. O estudo comportamental da roldana R3 proporcionou analisar particularidades interessantes devido aos quatro orifícios presentes em seu corpo o que implica em saber qual o melhor valor de $\alpha$. Com este intuito e a partir dos dados experimentais medidos tais como: raio da roldana; raio de cada furo; a distância aproximada do centro da roldana até o centro do furo e da massa da roldana foi possível calcular o valor aproximado de $\alpha$ como sendo 0,653. Para ratificar este valor, foram também realizadas dezoito atividades experimentais consistindo empreender ao sulco da roldana um corpo de massa conhecida através de um barbante e medido a velocidade do corpo ao passar por dois sensores de luz, postos a uma distância conhecida um do outro. Neste caso, o valor médio obtido de $\alpha$ foi 0,63. Assim, ao analisar o gráfico da Figura 5(C), fica evidente que para $\alpha$ em torno de 0,7 , o valor da aceleração da gravidade mais se aproxima do valor esperado da medida da aceleração da gravidade, que é 9,8 $\mathrm{m} / \mathrm{s}^{2}$.

Figura 5 - Dados experimentais obtidos com o Tracker para a aceleração do sistema em função das massas $M$ e $m$ para diferentes roldanas (A) R1; (B) R2 e (C) R3. O valor de $\alpha$ dependerá da distribuição de massa em torno do eixo de rotação

(B)
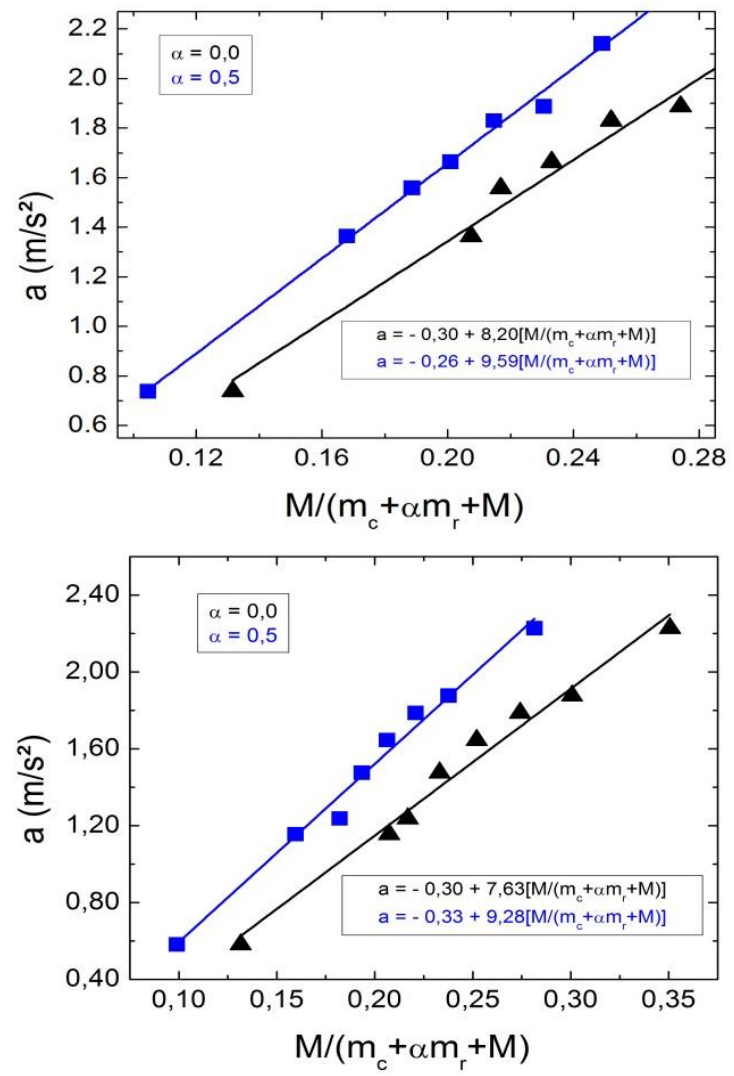


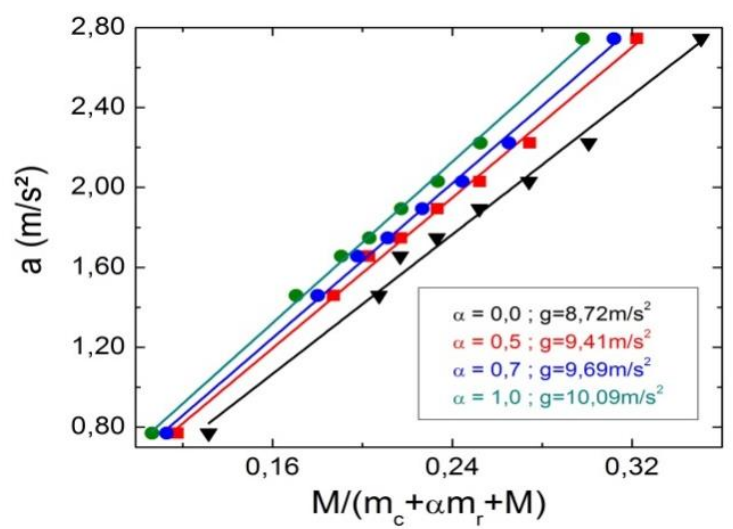

(Fonte: Autoria própria)

Há um aspecto fundamental na obtenção destes valores de $\alpha$, para o qual o professor deve dar especial atenção ao mediar a discussão. Há vários livros de Física Básica, Engenharia ou Cálculo Integral que demonstram a obtenção de momentos de inércia, como já foi citado, de objetos com alto grau de simetria. Entretanto, em uma situação real, como as roldanas aqui utilizadas, além do atrito nos mancais de rolamento, há, certamente, imperfeições na distribuição de massa das mesmas, devido a imperfeições no processo de usinagem destas peças. O procedimento de modelagem científica, aqui descrito, permite a obtenção do coeficiente $\alpha$ "real" de cada roldana, que certamente não seria o mesmo valor obtido analiticamente para uma roldana "ideal", sem atritos e com distribuição de massa perfeitamente uniforme. Ao analisar as discrepâncias entre os valores "real" e "ideal" de $\alpha$, o estudante de engenharia tem aqui mais um elemento para passar a incluir em suas análises de modelagem fatores externos e complementares a descrições físicas que não levam todos os aspectos da realidade em consideração. Vale salientar que mesmo em softwares de modelagem tridimensional, que fazem uso de CAD/CAM, estes efeitos são difíceis de serem modelados ou mesmo estimados. Isto implica que a metodologia de modelagem aqui descrita, em um experimento de física básica, pode ser estendida para disciplinas mais avançadas das matrizes curriculares de cursos de Engenharia, como Elementos de Máquinas, em um curso de Engenharia Mecânica. Deste modo, a articulação entre TIC, Laboratórios Didáticos, via uma metodologia baseada em Modelagem Científica, tem um caráter unificador para diversas componentes curriculares em um curso de Engenharia.

\section{Discussão e conclusão}

Neste trabalho apresentamos uma abordagem que emprega a videoanálise como instrumento para estimular a modelagem científica em aulas de laboratório de Física Básica. Para tal, propomos o uso do software livre Tracker enquanto OA mediador de atividades experimentais nas quais podem ser levados em conta aspectos do "mundo real", tais como forças dissipativas, inércia rotacional e falta de simetria na distribuição de massas de polias.

Muitas vezes, estudantes e professores despendem muito tempo e energia aprendendo o modus operandi dos equipamentos utilizados, notadamente quando do uso de kits didáticos em laboratórios, em detrimento da observação 
da evolução temporal e da análise das grandezas Físicas importantes. O uso destes kits didáticos para os quais são necessárias as conexões de diversos fios e o alinhamento de sensores requer um tempo operacional que, em geral, não é compatível com o tempo didático das aulas de Física. Isto, muitas vezes, dificulta a realização de atividades experimentais mais significativas. Daí a importância de metodologias portadoras de potencial para inserir elementos da modelagem científica. Neste contexto, demonstramos que o emprego do OA Digital Tracker em atividades experimentais (compatíveis com a realidade escolar brasileira) permite a inclusão de elementos que instigam a uma modelagem mais elaborada. Assim, entende-se que o uso do Tracker no ensino de Física e Engenharia é promissor por conta de seu baixo custo, de sua versatilidade e do interesse que desperta nos estudantes, tendo em vista a dinâmica de aulas em que permite a participação ativa dos estudantes e em uma posição em que os questionamentos decorrentes da metodologia proposta permitam formular, questionar, predizer, testar hipóteses- passos importantes em um processo de modelagem científica. Estas possibilidades denotam aulas em concordância com o exposto por Matsunaga (2015) e Celaya e Martínez (2007). Desta forma, justifica-se a nossa proposta de colocar a videoanálise como ferramenta mediadora da Modelagem Científica no Ensino de Física, onde mesmo usuários relativamente inexperientes são capazes de incorporar a visão da Física como uma Ciência em que parte dos seus métodos descritivos tem base em atividades experimentais de modelagem e, a partir destas, é possível formular relações entre grandezas físicas.

Para a percepção destas relações, é muito comum, nas situações de ensino, que a parte teórica e os exemplos e problemas abordados versem sobre situações "ideais", nas quais atritos entre superfícies, resistência do ar e massas de fios e polias são desprezados. As simplificações são tantas que acabam por induzir a um ensino em que as concepções científicas parecem ter pouco a ver com a realidade (CUPANI e PIETROCOLA, 2002). Este distanciamento entre as aulas de Física e a realidade dos estudantes é reportado como prejudicial ao processo de ensino: os estudantes não vêem utilidade nos conteúdos ensinados e, muitas vezes, é construída - ao contrário do que se pretende - uma visão negativa e deturpada da Ciência, como algo "pronto", que é fundamentada sobre "desprezar e simplificar" efeitos da realidade, causando aos estudantes dúvidas sobre a sua real aplicabilidade na descrição de efeitos e fenômenos mais complexos de um sistema físico ou de um projeto em Engenharia.

Deste modo, esta proposta, pela sua simplicidade de aplicação, potencialidade de discussões entre o "real" e o "ideal" colabora no impacto positivo na formação do físico e do engenheiro, via suas habilidades e competências, ao prepará-lo a observar, descrever e modelar situações complexas da realidade, correntes no exercício da Engenharia e da pesquisa em Física. 


\title{
Videoanalysis as a mediator of the scientific modeling in the Teaching of Mechanics
}

\begin{abstract}
Teaching and learning methodologies mediated by information and communication technologies (ICT ) play an important role in discussions about the school in this century. The Didactic Laboratory, in turn, is a place where methodologies are developed and articulated with ICT. In the teaching of Mechanics, scientific modeling is an alternative to the study of situations that are exclusively "ideal", which are not akin to practical reality. We discuss strategies based on the use of Videoanalysis for the development of experimental activities in order to incorporate scientific modeling in Mechanics classes. We show that the use of the free software Tracker, consisting of experimental activities mediated by ICT, allows the inclusion of elements that instigate a more elaborate modeling, favoring learning situations that lead to a less fragmented and more contextualized knowledge, and to a broader and better referenced view of science.
\end{abstract}

KEYWORDS: Mechanics teaching experimental activities, Information and Communication Technologies, Learning Objetcs, Videoanalysis, Scientific Modeling, Tracker. 


\section{REFERÊNCIAS}

ARANTES, A.R.; MIRANDA, M.S.; STUDART, N. Objetos de aprendizagem no ensino de física, Física na Escola, v.1, n.1, p.27-31, 2010.

ARAÚJO, I. S.; VEIT, E. A.; MOREIRA, M. A. Modelos Computacionais no EnsinoAprendizagem de Física: um Referencial de Trabalho. Investigações em Ensino de Ciências, v. 17, n. 2, p. 341-366, 2012.

BARBETA, V. B; YAMAMOTO, I. Desenvolvimento e Utilização de um Programa de Análise de Imagens para o Estudo de Tópicos de Mecânica Clássica. Revista Brasileira de Ensino de Física, v. 24, n. 2, p. 158-167, 2002.

BEER, F.P.; JOHNSTON, E.R. Mecânica Vetorial para Engenheiros, 5. ed. São Paulo: Makron, 1991.

BRANDÃO, R. V.; ARAUJO, I. S.; VEIT, E. A. A Modelagem Científica Vista Como um Campo Conceitual. Caderno Brasileiro de Ensino de Física, v. 28, n. 3, p. 507-545, 2011.

BROFFICE. Disponível em: <http://broffice.org/>. Acesso em: 14 Jul. 2012.

BROWN, D. Video Analysis and Modeling Tool for Physics Education. Disponível em: < http://www.cabrillo.edu/ dbrown/tracker/ >. Acesso em: 16 Jul. 2012.

BROWN, D.; COX, A. J. Innovative Uses of Video Analysis. The Physics Teacher, v. 47, p. 145-150, 2009.

BRYAN, J. A. Investigating the conservation of mechanical energy using video analysis: four cases. Physics Education, v. 45, n. 1, p. 50-57, 2010.

CATELLI, F; MARTINS, J. A.; SILVA, F. S. Um estudo de cinemática com câmara digital. Revista Brasileira de Ensino de Física, v. 32, n. 1, p. 1503(1-7), 2010.

CELAYA, C. L.; MARTíNEZ, S. L. D. Uso de software libre y de internet como herramientas de apoyo para el aprendizaje. Revista Iberoamericana de Educación a Distância, v. 10, n.1, p. 83-100, 2007.

CORVELONI, E. P. M.; GOMES, E. S.; SAMPAIO, A. R.; MENDES, A. F.; COSTA V. L. L.; VISCOVINI, R. C. Utilização de máquina fotográfica digital (multi-burst) para aulas experimentais de cinemática - queda livre. Revista Brasileira de Ensino de Física, v. 31, n. 3, p. 3504(1-4), 2009. 
CUNHA, F.M. Ensino de Engenharia: abordagem pela complexidade. Revista de Ensino de Engenharia, v. 34, n. 1, p. 3-16, 2015.

CUPANI, A.; PIETROCOLA, M. A. A relevância da epistemologia de Mario Bunge para o ensino de ciências. Caderno Brasileiro de Ensino de Física, v. 19, n. esp, p. 100-125, 2002.

DIONISIO, G.; MAGNO, W. C. Photogate de baixo custo com a porta de jogos do PC. Revista Brasileira de Ensino de Física, v. 29, n. 2, p. 287-293, 2007.

GAMA, C.L.G.; SCHEER, S.; SANTOS, M.C. Desenvolvimento de Objetos de Aprendizagem para o ensino e aprendizagem em Engenharia. Revista de Ensino de Engenharia, v. 27, n. 1, p. 17-23, 2008.

HAAG, R.; ARAUJO, I. S.; VEIT, A. E. Por que e como introduzir a aquisição automática de dados no laboratório didático de Física? Física na Escola, v. 6, n.1, p. 69-74, 2005.

LAUDERES, J.B.; PAIXÃO, E.L.; VIGGIANO, A.R. O ensino de engenharia e a formação do engenheiro: contribuição do programa de mestrado em tecnologia do CEFET-MG - Educação Tecnológica. Revista de Ensino de Engenharia, v. 27, n. 1, p. $8-16,2008$

MATSUNAGA, F. H. Objetos de Ensino, suas potencialidades e dificuldades para aprendizagem de Física no Ensino Médio. 2015. 67 f. Dissertação (Mestrado em Ensino de Ciências) - Programa de Pós-Graduação em Formação Científica, Educacional e Tecnológica, Universidade Tecnológica Federal do Paraná, Curitiba, 2015. Disponível em: <http://repositorio.utfpr.edu.br/jspui/handle/1/1633> Acesso em 06/10/16.

OLIVEIRA, H.P.; PASSOS, W.A.C. Ensino de Física Básica para as Engenharias: o caso da Univasf. Revista de Ensino de Engenharia, v. 33, n. 2, p. 9-14, 2014.

OLIVEIRA, L. P. et al. Divulgando e ensinando análise de vídeo em sala de aula: experimentos de mecânica com o software Tracker. In: XIX SIMPÓSIO NACIONAL DE ENSINO DE FÍSICA, 2011, Manaus. Anais... Disponível em: <http://www.sbf1.sbfisica.org.br/eventos/snef/xix/sys/resumos/T0094-1.pdf>. Acesso em: 16 Jul. 2012.

OPEN SOURCE PHYSICS (OSP). Disponível em: <http://www.compadre.org/osp/>. Acesso em: 16 Jul. 2012. 
PINHO ALVES, J. F. Atividades experimentais: do Método a Prática Construtivista. Tese de Doutorado. Universidade Federal de Santa Catarina, Florianópolis, 2000.

PINHO ALVES, J. F. Regras da transposição didática aplicadas ao laboratório didático, Caderno Brasileiro de Ensino de Física,v.21, n. esp., p.44-58, 2004.

ROCHA, F. S. da; FAJARDO, F., GRISOLÍA, M.; BENEGAS, J.; TCHITNGA, R.; LAWS, P. Using Student Technology in Introductory Physics: A Comparison of Three Tools to Study Falling Objects. The Physics Teacher, v 49, p. 165-167, 2011.

SCIDAVIS. Disponível em: <http://scidavis.sourceforge.net/>. Acesso em: 16 Jul. 2012.

SENA DOS ANJOS, A. J. As novas tecnologias e o uso dos recursos telemáticos na educação científica: a simulação computacional na educação em física. Caderno Brasileiro de Ensino de Física, v. 25, n. 3, p. 569-600, 2008.

SOUZA, A.P.A.; DELAMARO, M.C.; SALGADO, A.M.P.; CAMPOS, A. A valorização das competências na formação e atuação dos engenheiros: a visão de estudantes de uma instituição pública. Revista de Ensino de Engenharia, v. 34, n. 2, p. 19-30, 2015

WILEY, A. The Instructional Use of Learning Objects. Disponível em: < http://reusability.org/read/ >. Acesso em 20 Jun. 2012.

Recebido: 2016-08-10

Aprovado: 2016-10-16

DOI: $10.3895 /$ rbect.v10n3.4509

Como citar:

SAAVEDRA FILHO, N.C.; LENZ, J.A.; BEZERRA JR, A.G.; FLORCZAK, M.A.; GARCIA, V.G. A videoanálise como mediadora da modelagem científica no Ensino de Mecânica. Revista Brasileira de Ensino de Ciência e Tecnologia, v. 10, n. 3, 2017. Disponível em: <https://revistas.utfpr.edu.br/rbect/article/view/4509>. Acesso em: $x x x$

Correspondência:

Nestor Cortez Saavedra Filho nestorsf@utfpr.edu.br

Direito autoral: Este artigo está licenciado sob os termos da Licença Creative Commons-Atribuição 4.0 Internacional. 